Talía. Revista de estudios teatrales

ISSN-e 2659-806X

\title{
La investigación sobre teatro infantil y juvenil en España: estado de la cuestión
}

\author{
Berta Muñoz Cáliz*
}

Recibido: 20 de mayo de 2020 / Aceptado: 30 de junio de 2020

Resumen. El propósito de este artículo es reflejar cuál ha sido hasta ahora la situación de la investigación sobre teatro infantil en España. En él se ofrece un panorama de los estudios publicados desde los años 60 hasta la actualidad, abarcando especialmente repertorios de textos editados, obras de carácter historiográfico y estudios monográficos sobre autores, pues han sido estas principalmente las sendas que han recorrido hasta el momento los estudiosos de esta materia. Igualmente, en aquellos aspectos que aún no han sido suficientemente explorados, se ofrecen algunas de las fuentes documentales a las que puede acudir el investigador para emprender futuros estudios sobre esta materia.

Palabras clave: Teatro infantil y juvenil; Investigación teatral; Historia del teatro español; Fuentes documentales.

\section{[en] Research on Children's and Young People's Theatre in Spain: State of Play}

\begin{abstract}
The purpose of this article is to reflect what has been the situation of research on children's theater in Spain so far. It offers an overview of studies published from the 1960s to the present day, especially covering repertoires of edited texts, historiographic works and monographic studies on authors, as these have been the paths that scholars of this matter have traveled so far. Likewise, in those aspects that have not yet been sufficiently explored, some of the documentary sources that the researcher can go to undertake future studies on this matter are offered.
\end{abstract}

Key words: Children's and Youth Theater; Theatrical research; History of Spanish Theater; Documentary sources.

Cómo citar: Muñoz Cáliz, B. (2020). La investigación sobre teatro infantil y juvenil en España: estado de la cuestión, en Talía. Revista de estudios teatrales, 2, 5-15.

La investigación sobre teatro para niños hoy en España se encuentra en un momento de cambio y de impulso renovado, y así se pudo comprobar en el Congreso Los márgenes de la periferia: Crear, editar, investigar y traducir poesía y teatro para niños y jóvenes, celebrado en Toledo en septiembre de 2019. Un repaso por la bibliografía más actual demuestra que en los últimos tiempos se ha producido un cambio sustancial en la percepción de este teatro por parte de la comunidad investigadora, que durante décadas apenas le había prestado atención, con las excepciones que comentaremos.. De hecho, hasta fechas muy recientes tan solo existían unos cuantos libros de referencia, tan valiosos como esporádicos en el panorama de la investigación literaria en España [Bravo Villasante 1959; Cervera, 1982; Fernández Cambria 1987; Tejerina 1993, 1994a], a los cuales iremos haciendo referencia a lo largo de estas páginas.

Afortunadamente, en la actualidad nos encontramos ante un interés creciente no solo por parte de aquellos educadores que trabajan directamente con niños y jóvenes (a quienes se ha dirigido tradicionalmente buena parte de la bibliografía existente sobre este tema, lo que explica su carácter práctico y orientado al trabajo en las aulas), sino también por parte de la investigación universitaria; pues lo cierto es que, el teatro para niños brilla por su ausencia en las historias del teatro español publicadas hasta nuestros días ${ }^{1}$. En los últimos tiempos, la consciencia de la necesidad de cuestionar y reformular el canon, junto con el auge de los estudios de género y el interés por las obras escritas por autoras, han impulsado la investigación sobre esta materia, pues, tradicionalmente,

CDAEM (Ministerio de Cultura y Deporte)

A modo de ejemplo, en su reseña de la obra de Juan Cervera Historia crítica del teatro infantil español, Javo Rodríguez señalaba la ausencia de importantes autores y obras de teatro infantil en las historias del teatro español de Ruiz Ramón [1975] y Oliva [1989] para destacar la escasa atención que habían recibido este tipo de obras hasta ese momento [Rodríguez 2003: 40]. Se podrían añadir otras obras de carácter historiográfico [Berenguer 1988; Oliva 2002; García Ruiz y Torres Nebrera 2002-2006; Huerta Calvo 2003; González Subías 2019]; y muchas otras cuya sola enumeración engrosaría considerablemente la bibliografía final. 
el teatro para niños ha sido un territorio en el que las dramaturgas han realizado múltiples y valiosas aportaciones. En este trabajo trataremos de reflejar los avances que se han producido en los últimos años, pero también de mostrar lo mucho que hay por hacer para futuros investigadores que decidan trabajar sobre esta materia.

\section{La elaboración del corpus de obras dramáticas: bibliografías e inventarios}

La elaboración de compendios e inventarios que permitan conocer el corpus de obras que posteriormente se va a analizar supone una de las primeras tareas a abordar para quienes emprendan una labor historiográfica. No obstante, en la materia que nos ocupa, con frecuencia este tipo de trabajos de recopilación bibliográfica se han encaminado a una finalidad práctica, como es la de informar a maestros, bibliotecarios, libreros y otros mediadores de los textos que tenían a su disposición a la hora de escoger lecturas para los niños o para ponerlos en escena en las aulas. En este sentido, uno de los trabajos pioneros lo llevó a cabo Aurora Díaz Plaja, bibliotecaria, escritora y traductora que, ya a comienzos de los sesenta, incluyó un "Ensayo de bibliografía de obras teatrales publicadas" dentro de su artículo "El teatro, ese género difícil de editar" [Díaz Plaja 1963]; en él se incluían sobre todo obras dramáticas publicadas en España, si bien, en un intento de abarcar todos los textos publicados en lengua española, añadió igualmente ediciones argentinas y uruguayas.

A mediados de los 80, toman el testigo en esta labor la profesora Julia Butiñá y la dramaturga Nuria Tubau, quienes presentan un repertorio mucho más amplio y detallado, que incluía obras editadas en las cuatro lenguas oficiales. Su publicación vio la luz en un número monográfico del Boletín Iberoamericano de Teatro para la Infancia y la Juventud [Butiñá y Tubau 1985], editado por la Asociación Española de Teatro para la Infancia y la Juventud, publicación periódica que durante décadas ha sido la única en nuestro país especializada en este ámbito. A esta edición le seguiría una versión actualizada llevada a cabo por Butiñá en solitario, con obras en lenguas española y catalana [1992], y, una nueva edición actualizada en 2002, realizada en colaboración, que incluía igualmente obras en español y catalán [Butiñá, Llorente Javaloyes y Muñoz Cáliz 2002]. Todos estos repertorios están organizados alfabéticamente, a modo de catálogos, e incluyen los datos bibliográficos básicos junto con una sinopsis argumental y el número de personajes de cada una de las obras; es decir, información para el profesor que desea ponerlas en escena o hacer lecturas dramatizadas en el aula, pero también para las compañías que buscan textos para representar ante un público infantil.

Yo misma continué este trabajo cuatro años más tarde, con Panorama de los libros teatrales para niños y jóvenes [Muñoz Cáliz 2006]; a diferencia de los libros anteriores, la información sobre las obras aparece estructurada por temas y por su tratamiento, si bien al final del libro se incluye una bibliografía con idéntico afán de exhaustividad y puesta al día. Y aunque, en este caso, no se trate de panoramas bibliográficos más o menos completos sino de selecciones realizadas a partir de los textos editados durante el año, hay que citar igualmente los artículos publicados durante la primera década de nuestro siglo en la revista Lazarillo, de la Asociación de Amigos del Libro Infantil y Juvenil: anualmente esta revista publica un monográfico sobre las publicaciones infantiles del año anterior, con reseñas de una selección de ellas en todos los géneros, incluido el teatro (algo poco frecuente en este tipo de revistas, dedicadas esencialmente a la narrativa); durante nueve temporadas se dio noticia del panorama editorial de este género y se reseñaron los textos más destacados [Muñoz Cáliz 2001, 2003, 2004, 2005, 2006b, 2007, 2008, 2009 y 2010].

El conjunto de obras hasta aquí citadas permite reconstruir el corpus de textos teatrales para niños publicados en España desde los años 60 hasta 2010. Como se dijo, estos repertorios de textos con frecuencia se han realizado con una finalidad práctica, debido a la necesidad que maestros y profesores de Secundaria tienen de este tipo de obras, y a la escasa distribución que los libros de teatro infantil suelen tener en las librerías; a su vez, esto ha determinado que muchas de las bibliografías citadas se centraran en obras recientemente publicadas y fácilmente accesibles para los lectores infantiles. Si quisiéramos reconstruir el corpus de textos teatrales para niños a lo largo de la historia del teatro español, tendríamos que recurrir a otro tipo de catálogos. Aunque también en este ámbito es mucho lo que queda por hacer, un trabajo imprescindible en este sentido es el de $\mathrm{M}^{\mathrm{a}}$ Antonia García de Rivera, El teatro escolar en la época contemporánea (1870-1970). Catalogación de 1.001 textos dramáticos escolares [García de Rivera 2010]; se trata de una Tesis Doctoral en la que esta investigadora, junto con la bibliografía descriptiva de los textos (que se ofrece en forma de anexo), ofrece un recorrido por las principales colecciones y editoriales que se han dedicado a este género, y da cuenta de las bibliotecas españolas en las que se puede acceder a las mismas. Un punto de partida necesario para emprender la historia del teatro español desde el último tercio del siglo XIX, teniendo en cuenta un tipo de textos, muy próximos a la enseñanza religiosa, que no siempre se incluyen en los estudios literarios pero que han tenido un peso indudable en la conformación del género teatral infantil. Y aunque no se trate de una fuente dedicada de forma específica al teatro para niños, los dos volúmenes que componen el diccionario Autoras en la historia del teatro español (15001994) [Hormigón 1996] constituyen una fuente impagable para los estudiosos de esta materia, pues, como se dijo, la literatura para la infancia ha constituido uno de los escasos territorios en el que las mujeres han podido actuar a lo largo de la historia.

En la actualidad, con los medios tecnológicos de que disponemos, parece lógico, y deseable, que las investigaciones bibliográficas que se acometan en un futuro se aborden en forma de bases de datos digitales, y a ser posible, integrando el trabajo de diferentes especialistas; los propios catálogos en línea de las bibliotecas y editoriales especializadas suponen un punto de partida más 
que interesante en este sentido, por la cantidad de información que contienen y por la actualización continua de la misma. De esta manera, los interesados podrían solicitar los libros en la biblioteca en la que se encuentren, leer algunas de sus páginas (a través de herramientas como Google Books, por ejemplo) o completar la información que le ofrecen los registros bibliográficos con enlaces a otras páginas, por poner algunos ejemplos. Por el momento, los catálogos de bibliotecas especializadas como la de ASSITEJ-España o la del CDAEM² pueden orientar a los lectores sobre los autores, títulos y colecciones que actualmente están editando obras para niños y jóvenes en España. También hay que destacar la labor que desde hace décadas viene elaborando la Fundación Germán Sánchez Ruipérez a través de su Canal Lector (2020, en línea), una herramienta de gran repercusión entre maestros y profesores, que en los últimos tiempos ha incluido más de setenta obras de teatro; a diferencia de los catálogos antes citados, esta base de datos opera con un criterio selectivo y junto con la sinopsis argumental de la obra, ofrece la valoración que un experto hace de la misma. Una recopilación bibliográfica hoy necesariamente tiene que integrar y visibilizar todos estos recursos, además de descubrir otros menos visibles y aportar nuevos contenidos y nuevos enfoques.

\section{Aproximaciones panorámicas a la historia del teatro infantil español}

Una obra pionera en abordar la historia del teatro infantil en nuestro país fue Literatura infantil española, de Carolina Toral [1957], que, en sus páginas dedicadas al género dramático, daba noticia de las adaptaciones para niños que se habían realizado a partir de los clásicos de la literatura dramática española: desde algunas piezas breves del Renacimiento hasta el teatro del siglo XIX (Martínez de la Rosa, García Gutiérrez, Galdós...), pasando por las adaptaciones de los autores del Siglo de Oro (Lope de Vega, Calderón, Rojas Zorrilla, Moreto...) y de la Ilustración (Moratín, Ramón de la Cruz...); además, en el capítulo dedicado al siglo XX, Toral valoraba la labor como autores de teatro para niños de dramaturgos como Eduardo Marquina, Jacinto Benavente o los hermanos Álvarez Quintero, entre otros. Dos años después, la Historia de la literatura infantil española de Carmen Bravo Villasante [1959] dedicaba igualmente parte de sus páginas al género dramático. De acuerdo con las pautas de la historiografía teatral del momento, esta autora se centró sobre todo en la historia de la literatura dramática (al igual que había hecho Toral). En su recorrido histórico por el género, Bravo Villasante se remontaba a los primeros tiempos del teatro español, concretamente a las piezas de Juan del Encina y Lope de Rueda, considerando como teatro infantil todas aquellas formas teatrales de las que el niño participa como espectador o como lector, al igual que hará, años más tarde,
Juan Cervera. En su amplia erudición sobre esta materia, esta autora no pierde de vista el teatro para niños realizado en otros países del entorno europeo, de manera que, al referirse a la influencia que ejerce Francia en este ámbito a partir de la Ilustración, menciona obras como $E l$ teatro de los niños, de Armand Berquin, que unos años después se traduciría y se difundiría en España. Bravo Villasante dedica breves apartados al teatro en todos sus capítulos, si bien es cierto que tanto la lírica como, sobre todo, la narrativa tienen un peso muy superior en su obra. Consciente de ello, añade un capítulo específico sobre "El teatro de los niños": diez páginas en las que repasa el teatro realizado en España desde Benavente hasta finales de los años 70 .

Mucho más ambiciosa en lo que se refiere al género que nos ocupa fue la Historia crítica del teatro infantil español de Juan Cervera [1982], obra por la que su autor recibiría el Premio Nacional de Literatura Infantil en su modalidad de Investigación: en ella, este investigador se remonta hasta el teatro religioso de la Edad Media y continúa hasta el momento de cerrar la escritura de su obra, a finales de los años 70. Si Bravo Villasante se había limitado a la literatura dramática, Cervera abarcaría además otros aspectos, como la participación del niño como actor en ciertas obras de teatro religioso desde la Edad Media, la presencia del teatro en las escuelas, la instrumentalización del género realizada por los salesianos, la edición de colecciones de teatro para niños, la presencia del género en radio y televisión, o la creación de compañías como Los Títeres o el Teatro Municipal Infantil durante la dictadura franquista, por poner algunos ejemplos. Al día de hoy no se ha vuelto a publicar ninguna otra obra que ofrezca una visión global de la historia del género en su conjunto, por lo que el libro de Juan Cervera continúa siendo, casi cuarenta años después de su publicación, la principal obra de referencia en esta materia.

En fechas muy próximas a la publicación de la obra de Cervera, Antonio Mendoza Fillola dedicó su Tesina de Licenciatura a El Teatro Infantil Español. Aspectos sociales (1875-1950); un estudio pionero en abordar esta materia desde un enfoque sociológico. Aunque de esta investigación solo se publicó un cuadernillo con una versión resumida, muy difícil de encontrar en la actualidad [Mendoza Fillola 1980], años después se publicaría una versión revisada [1998]. Los años 80 fueron sin duda años fructíferos en este terreno; un lustro después de la publicación de la obra de Juan Cervera, Elisa Fernández Cambria publicaba su monografía Teatro español de siglo XX para la infancia y la juventud. (Desde Benavente hasta Alonso Santos); tal como anuncia su título, los dramaturgos y sus textos volvían a ser los protagonistas absolutos de este estudio, en el que su autora analizaba una serie de obras con atención y profundidad hasta entonces inéditas: Linares Rivas, Martínez Sierra, Valle-Inclán, Gómez de la Serna, García Lorca, Alfonso Sastre o Jesús Campos son algunos

ASSITEJ-España cuenta con una biblioteca especializada en teatro infantil y juvenil compuesta por más de 2.300 títulos. El Centro de Documentación de las Artes Escénicas y la Música (CDAEM), heredero del anterior Centro de Documentación Teatral (CDT), por su parte, cuenta con una sección dedicada a esta materia, compuesta por unos 500 libros infantiles, dentro de su amplia colección de teatro, además de otro tipo de materiales documentales a los que nos referiremos más adelante. Tanto el catálogo de ASSITEJ-España como el del CDAEM están disponibles en línea, en las webs de sus respectivas entidades: https://www.assitej.net/ y http://cdaem.mcu.es/. 
de los quince dramaturgos aquí abordados [Fernández Cambria 1987].

Desde entonces, habrá que esperar casi dos décadas para encontrar un nuevo intento de reconstruir la historia del teatro infantil español del pasado siglo; será la investigadora Isabel Tejerina, gran conocedora de este género, quien presente un sintético "Panorama histórico del teatro infantil en castellano", en el que realiza un repaso por quince obras canónicas del género a lo largo del siglo XX, concretamente desde 1910 hasta 2000, en un encomiable intento de continuar hasta el final del pasado siglo el trabajo de quienes la precedieron, presentando una selección comentada de textos [Tejerina 2007]. Aunque aborda igualmente aspectos relacionados con la escena y con la sociología del fenómeno teatral infantil, Tejerina se centra sobre todo en el estudio de las obras dramáticas. Por el momento, el intento más reciente de continuar esta labor es el de Ahumada Zuaza [2015a y 2015b], que abarca desde las manifestaciones del Simbolismo en el teatro infantil de principios del siglo XX hasta la primera década del presente siglo. Además de las obras en lengua española, el teatro en el resto de lenguas oficiales del Estado también ha sido objeto de estudios específicos: gallego [Roig Rechou y López Suárez 2007]; catalán [Luna 2007] y vasco [Etxaniz Erle y López Gaseni 2007].

Junto a las obras ya citadas de Toral y Bravo Villasante, otros importantes estudios de carácter histórico sobre teatro infantil han formado parte de obras que abordan la historia de la literatura infantil en su conjunto. Es el caso de los trabajos de Jaime García Padrino: Libros y literatura para niños en la España contemporánea [1992], e Historia crítica de la literatura infantil y juvenil en la España actual (1939-2015) [2018], obra complementaria de la anterior. La primera de estas obras se remonta hacia 1885 , momento en que la literatura infantil comienza a convertirse en una industria creada para un mercado y un sector de edad muy específicos; y aunque contenía un apéndice sobre la literatura infantil desde la posguerra hasta 1991, en realidad el estudio más detallado finalizaba en 1939. Una tarea que el autor completa con creces en la obra publicada en 2018, que abarca desde la posguerra hasta el momento actual. En sendas obras, García Padrino estudia a los autores y sus textos, pero también las colecciones, las editoriales, los modelos educativos a los que responden las obras analizadas y otros aspectos tanto estéticos como de carácter sociológico.

Junto con la necesidad de trazar un recorrido diacrónico por la historia del teatro, el acercamiento a las constantes del género, más allá de las circunstancias históricas en que las obras fueron escritas, ha sido otro de los objetivos de los investigadores en esta materia. En 1993, Isabel Tejerina había dado a conocer un trabajo que marcaría un hito en la investigación sobre la materia que nos ocupa: Estudio de los textos teatrales para niños [1993]. Si las obras de Bravo Villasante, Cervera y Fernández Cambria tenían carácter historiográfico, el trabajo de Tejerina, aunque abarca un período igualmente amplio (desde principios del siglo XX hasta el momento en que la obra fue publicada), se presenta en forma de análisis estructural basado en los estudios de Vladimir Propp sobre los cuentos de hadas. Por mi parte, en Panorama de los textos teatrales para niños y jóvenes procuré igualmente acercarme a los textos desde la perspectiva de los cuentos tradicionales, precisamente para comprobar en qué medida los autores más recientes alteraban y deconstruían estas estructuras con el fin de dirigirse a los niños del siglo XXI, pues, en este caso, el arco cronológico se limitaba a los textos que en aquel momento formaban parte de las colecciones editoriales vigentes [Muñoz Cáliz 2006]. Por otra parte, un acercamiento teórico al fenómeno es el que propone María Victoria Sotomayor en "Literatura dramática infantil: texto y representación" [Sotomayor 2007].

\section{Estudios monográficos: desde el siglo XIX hasta la guerra civil}

Al margen de las obras medievales que requerían la participación de niños o de los pasos y sainetes del Siglo de Oro que, por su brevedad y sencillez, se han considerado como apropiados para este público, el fenómeno de los creadores que escriben y representan obras dirigidas expresamente al público infantil se remonta en nuestro país a finales del siglo XIX, si bien con anterioridad existen precedentes en el teatro escolar de órdenes religiosas como los jesuitas o los escolapios, tal como analizó Cervera en su obra citada [1982]. Lara Alberola [2010] profundiza en este fenómeno centrándose en un texto de José de Villarroya especialmente representativo del teatro escolar del siglo XVIII.

En los últimos años del siglo XIX y principios del XX, uno de los géneros pioneros en dirigirse al público más joven sería la zarzuela. De hecho, apoyándose en zarzuelas históricas que se hicieron para niños, en fechas relativamente recientes, el madrileño Teatro de la Zarzuela lanzó un programa pedagógico en el que recuperó algunas de ellas, como El paraíso de los niños, escrita en colaboración Carlos Arniches y Sinesio Delgado. Poco o casi nada sabemos, sin embargo, de este fenómeno de las zarzuelas para niños, exceptuando los trabajos de Rodríguez Lorenzo [2018] sobre dos compañías infantiles de zarzuela en las dos últimas décadas del XIX, de manera que se trata de un territorio donde casi todo está por hacer.

Más allá del género musical, durante el último cuarto del siglo XIX se escriben un importante número de obras para niños a cargo de autores como María Soto y Sáez, Maximiliano M. Monje, Francisco Pi y Arsuaga o Juan Francisco Piferrer, buena parte de las cuales se publicaron en la editorial de Saturnino Calleja. Gracias a la labor del Centro de Estudios de Promoción de la Lectura y la Literatura Infantil (CEPLI), algunas de ellas se encuentran publicadas en línea en la Biblioteca Virtual Miguel de Cervantes, en la que se pueden leer libremente $^{3}$. Jaime García Padrino se acerca a este tipo de obras en su citado estudio [1992] e igualmente, el libro de Itziar Pascual Teatro español para la infancia y la juventud (1800-1936) -que, pese a su título, se centra en los 
años del cambio de siglo- es uno de los escasos estudios sobre la literatura dramática de este período; además, incluye las ediciones de tres obras comprendidas entre 1898 y 1910 [Pascual 2008].

Ya en los inicios del siglo XX, la experiencia mejor estudiada hasta el momento es el Teatro de los Niños de Jacinto Benavente, de la que contamos con un exhaustivo y clarificador estudio a cargo de Javier Huerta Calvo [2012]. El dramaturgo madrileño es autor de una de las piezas mejor conocidas del teatro anterior a la guerra civil y una de las pocas que hoy se consideran canónicas de este género: El príncipe que todo lo aprendió en los libros; Isabel Tejerina alude en varias ocasiones a ella dentro de sus numerosos e imprescindibles estudios sobre el género, y a ella se le ha dedicado algún artículo específico [Borham Puyal 2018]; aunque no han corrido la misma suerte el resto de obras -cinco en total- que Benavente escribió para el público infantil. Pero si hay un texto de este período que ha sido valorado como pieza fundamental del canon del teatro infantil español es la Farsa infantil de La cabeza del dragón, de Ramón María del Valle-Inclán; no solo es la más reeditada, sino también la más estudiada y sobre la cual existe un mayor número de artículos publicados, aunque, lo que no deja de ser irónico, no todos sus estudiosos coincidan en considerarla como una obra infantil [Rubio Jiménez 1987; Burguera 1991; García Padrino 1992; Tejerina 2001; Sánchez Laílla 2004; entre otros]. El otro gran proyecto de teatro infantil llevado a cabo en la España de estos años, las campañas infantiles del Teatro de Arte de los Martínez Sierra, ha sido objeto de un estudio monográfico [Aguilar Hernández 2016], aunque todavía es mucho lo que queda por averiguar acerca de la que sin duda es una de las experiencias más interesantes de la primera mitad del siglo XX.

Desde entonces, hay que dar un salto cronológico hasta los años 20 y 30 para volver a encontrar estudios sobre el teatro infantil español y sobre algunos de sus creadores, entre los que se encuentran García Lorca [Hernández Sánchez 1992], Alejandro Casona [Tejerina 1994b, 1998; Ruiz 2008a y 2008b], Concha Méndez [Nieva de la Paz 2001; Bernard 2006; Bados Ciria 2009; Barrantes 2017; Molina-Angulo 2018-2019], Salvador Bartolozzi [Vela Cervera 2004] y Elena Fortún [Mascarell 2018; Molina-Angulo y Selfa Sastre 2019]. Tanto Méndez como Fortún, junto con Magda Donato (menos estudiada que las anteriores), fueron abordadas por Pilar Nieva de la Paz en Autoras dramáticas españolas entre 1918 y 1936 [1993], obra que marcó un antes y un después en el conocimiento del teatro infantil de este período, pues muchas de estas obras fueron escritas precisamente por dramaturgas, invisibles hasta entonces. Las tres dramaturgas citadas han sido abordadas recientemente por Molina Angulo en una Tesis Doctoral inédita en el momento de redactar estas páginas [2019].

\section{Estudios monográficos: la posguerra y la Transición política}

Tanto la pareja formada por Bartolozzi y Donato como Alejandro Casona, Concha Méndez y Elena Fortún par- tieron al exilio en 1939, como también otros autores que escribirían teatro para niños y jóvenes en sus respectivos países de acogida: Antonio Robles Soler (Antoniorrobles), María Martínez Sierra, Josefina Plá, León Felipe, Alfredo Pereña, Rafael Alberti, Herminio Almendros o César M. Arconada, entre otros. El teatro que escribieron los exiliados con posterioridad a la Guerra Civil fue prácticamente desconocido hasta 2008, año en que se publica

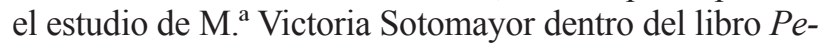
queña memoria recobrada. Libros infantiles del exilio de 1939: un trabajo de conjunto que ofrece una visión panorámica del teatro infantil escrito por estos autores en distintos países de Europa y América. Unos años después se publicaría una monografía fundamental sobre la literatura infantil del exilio republicano en México, que contiene igualmente capítulos dedicados al teatro para niños [Cerrillo y Miaja 2013]. Pese al indudable interés de muchos de los textos infantiles del exilio, al día de hoy, la gran mayoría de ellos continúan sin haber sido editados en España, de manera que es necesario recurrir a ediciones hispanoamericanas de los años 40 y 50 para poder conocerlos. Sin duda es una de las deudas pendientes más acuciantes en la materia que nos ocupa que atañe por igual a investigadores, editores e instituciones oficiales. Entre las excepciones, cabe citar las ediciones, acompañadas de rigurosas introducciones, de las obras de Magda Donato [Vicente 2000] y María Martínez Sierra [Aguilera y Lizárraga 2018]. Recientemente, el teatro infantil de Josefina Plá ha sido incluido en una Tesis Doctoral sobre la obra teatral en su conjunto de esta dramaturga exiliada en Paraguay [Yousfi 2019].

Mientras tanto, en la España de Franco, recién acabada la guerra se publican manifiestos sobre cómo debe ser el teatro para niños en el Nuevo Estado, se representan obras infantiles en distintos teatros comerciales (principalmente durante las campañas de Navidad) y se crean compañías de títeres. Una fuente inestimable para conocer la escena infantil durante la primera década de la dictadura es la colección que, bajo el título Documentos para la Historia del Teatro Español, ha venido publicando el CDAEM (antes Centro de Documentación Teatral), con prensa digitalizada, programas de mano, fotografías y otros documentos del teatro comprendido entre 1939 y 1948, además de un buscador de estrenos que permite localizar los espectáculos estrenados año a año (Centro de Documentación de las Artes Escénicas y de la Música, 2011-2019). En cuanto a bibliografía, esta primera etapa del franquismo fue abordada en mi artículo "Falangismo y teatro infantil" [Muñoz Cáliz 2016], centrado en los proyectos iniciales de los ideólogos del régimen sobre esta materia. Partiendo sobre todo de la prensa local, Álvaro Anabitarte reconstruye parte de la vida teatral en Navarra durante la guerra civil y la inmediata posguerra; especialmente, el teatro infantil vinculado a las entidades religiosas, que tanta presencia han tenido a lo largo de la historia en el desarrollo de este género [Anabitarte 2019a y 2019b].

Como el resto de las obras que se representaron en los escenarios españoles durante la dictadura, el teatro infantil también sufrió la actuación de la censura; este aspecto de nuestra historia teatral ha sido estudiado a 
través de los expedientes de autores como Gloria Fuertes, Lauro Olmo y Pilar Enciso, demostrando que este teatro sufrió una censura tan estricta $-\mathrm{y}$ en no pocos casos, tan absurda en sus dictámenes- como el dirigido a los adultos [Muñoz Cáliz y Sotomayor Sáez 2016; Arnaud 2016]. Uno y otro estudio se presentan a modo de calas en un período que, por amplio y complejo, aguarda aún a ser analizado a fondo. En lo que se refiere a estudios sobre autores concretos, la Tesis Doctoral de Luis Ahumada Zuaza sobre el teatro infantil y juvenil de Carmen Conde, elaborada a partir del estudio directo de su archivo personal, es el estudio de mayor alcance realizado hasta hoy en este sentido. No tenemos noticia, en cambio, de ninguna investigación sobre el teatro para niños de otras autoras de este período, como Gloria Fuertes (de quien se conserva incluso un libreto inédito y prohibido en el Archivo General de la Administración), Liboria Casas Regueiro (Borita Casas) o Josefina Solsona Querol.

Mayor atención hasta el momento ha recibido el período comprendido desde 1960 hasta el final de la dictadura, gracias a la Tesis Doctoral de Simon Arnaud [2018], donde se estudian sobre todo los textos publicados en las distintas colecciones y editoriales de estos años de desarrollismo y posterior decadencia del Régimen, aunque se atiende igualmente a factores como la censura, la creación de compañías oficiales como Los Títeres de la Sección Femenina y de asociaciones profesionales como AETIJ; todos ellos de importancia capital en el teatro infantil de este período. En un intento de presentar una visión sintética del teatro de la dictadura franquista en su conjunto, yo misma publiqué un trabajo de carácter panorámico que abarcaba igualmente los años de la Transición política, apuntando algunos de los principales hitos en cuanto a autores, compañías y publicaciones, aunque, por las características del trabajo, no fue posible ahondar en detalles [Muñoz Cáliz 2011]. Tampoco abundan los estudios sobre dramaturgos y obras concretas de este período, aunque sí contamos con un trabajo que aborda de forma conjunta el teatro infantil de Ricardo López Aranda, Lauro Olmo y Pilar Enciso [Santolaria 2001].

Desde mediados de la década de los 60, varias revistas teatrales emblemáticas comenzarían a publicar números monográficos dedicados al teatro para niños, desde el convencimiento de que la lucha del teatro por una sociedad democrática no podía prescindir de este sector del público. Entre ellas, la barcelonesa Yorick fue una de las primeras en interesarse por esta materia [n. 23, 1967], a la que dedicó artículos y crónicas en distintos momentos; pronto le seguiría la madrileña Primer Acto [n. 96, 1968], que a lo largo de su dilatada trayectoria ha vuelto a abordarlo en varios monográficos ${ }^{4}$. También por entonces surgen una serie de compañías infantiles de carácter oficial, abordadas en parte en el estudio de Arnaud, sobre las cuales está pendiente realizar estudios monográficos que arrojen luz sobre este período.

La investigación sobre el teatro de títeres requeriría por sí sola un estudio detallado sobre su estado de la cuestión; aunque no siempre se destinó a la infancia, es indudable que una buena parte de estas creaciones se han dirigido tanto a los niños como al público popular (dos públicos que en numerosas ocasiones han sido convergentes y a los que también se han dirigido de forma conjunta algunos de los principales dramaturgos del género, como Alejandro Casona). El teatro de títeres a lo largo del siglo XX ha sido objeto de un importante trabajo de síntesis por parte de Jesús Rubio: desde Valle-Inclán y García Lorca, y el Teatro Pinocho de Bartolozzi y Donato en la España anterior a la guerra civil hasta los títeres de Maese Villarejo o de Talio en la posguerra, a los que seguirían Francisco Porras y su compañera Tina Gascó, Francisco Peralta o Ángeles Gasset, para finalizar con las compañías que surgen en la Transición, como La Claca o La Tartana [Rubio 2016]. El trabajo de Rubio aporta además una completa bibliografía que permite profundizar en esta materia. Así mismo, Tejerina [2000] ofrece igualmente un panorama sintético del teatro de títeres para la infancia desde García Lorca hasta finales del siglo XX, mientras que Ayuso [2016] ofrece un recorrido de gran interés por la historia del teatro de títeres en nuestro país; en este caso sin ceñirse únicamente a los espectáculos dedicados a la infancia, pero abordándolos igualmente. Desde 2012, la revista Fantoche. Arte de los Títeres, editada por la Unión Internacional de la Marioneta (UNIMA), está dedicada íntegramente a esta materia, como con anterioridad, desde 1988, lo estuvo Puck. La marioneta y las otras artes, cuya versión española fue editada por el Centro de Documentación de Títeres de Bilbao.

\section{Estudios monográficos: desde la Transición a nuestros días}

A partir de la Transición política, la esperanza de cambio social va a estar acompañada de una serie de proyectos por parte de dramaturgos que se interesan por el teatro para niños y van a renovar el género, como Jesús Campos [Santolaria Solano 2001; Muñoz Cáliz 2012] y Luis Matilla [López Askasibar 2011 y 2018; Gobbé-Mévellec 2012] en el ámbito del teatro profesional, y Alfonso Jiménez Romero en la esfera del teatro escolar [Mora Álvarez 2015]. También en la Transición surgen compañías de títeres como La Claca o La Tartana [Muñoz y Muñoz 2017], que introdujeron nuevos lenguajes en el teatro infantil de su tiempo. En fechas muy próximas, a principios de los años 80 , comienza a escribir su teatro infantil José Luis Alonso de Santos, cuya producción para niños ha sido objeto de una Tesis Doctoral [Rodríguez González 2017]. En un trabajo de carácter panorámico, Cristina Santolaria aborda la producción de otros autores de este período: Alberto Miralles, Fermín Cabal, los ya citados Campos y Alonso de Santos y, ya a partir de los años 80, Ignacio del Moral [Santolaria Solano 2001].

En los últimos años, el florecimiento que ha tenido este teatro en España en lo que se refiere a puestas en es-

Tanto los índices de Yorick como los de Primer Acto (hasta su n. 300) se pueden consultar en la web http://teatro.es/catalogo-integrado; en el caso de Yorick, además, se pueden leer en dicha página todos los artículos a texto completo en formato digital. 
cena y compañías dedicadas al público infantil no se ha correspondido, hasta el momento, con la respuesta que ha obtenido por parte del mundo académico y de la comunidad investigadora. De hecho, la labor historiográfica de los autores citados en epígrafes anteriores no ha tenido continuidad, de manera que carecemos de una historia del teatro infantil español desde los años 80 hasta nuestros días; labor para la que el historiador actual dispondría, como es previsible, de una cantidad de recursos $\mathrm{y}$ fuentes documentales muy superior a la que tuvieron sus antecesores: desde colecciones de obras dramáticas (mucho más sencillas de localizar que las colecciones de preguerra y, por supuesto, que los textos del exilio, en bibliotecas como la Nacional de España o las citadas del CDAEM y de ASSITEJ-España) hasta fotografías, fonogramas y grabaciones en vídeo, gracias a fondos como el que desde los años 70 se fue formando dentro del Centro de Documentación Teatral (actualmente, como se dijo, convertido en Centro de Documentación de las Artes Escénicas y de la Música), así como a la posibilidad de obtener materiales de las propias compañías en activo a través de sus sitios web o incluso del contacto directo con sus componentes. En cualquier caso, además de las ya citadas grabaciones y fondos audiovisuales, desde los años 80 el Centro de Documentación Teatral fue elaborando una base de datos de espectáculos estrenados en España que, al día de hoy, incluye más de 47.000 fichas de estrenos entre 1939 y 2020. Desde 1985, año en que comenzó a publicarse el Anuario Teatral de España, los documentalistas del Centro completan esta base de datos intentando reconstruir de forma exhaustiva todos los montajes estrenados en cada temporada. A ello se suma el hecho de que nunca como en las últimas décadas se han estrenado tantos espectáculos de teatro infantil en nuestro país, por lo que esta base de datos se constituye en una fuente fundamental para futuros historiadores de esta materia.

Por otra parte, revistas teatrales como ADE Teatro [n. 80, 2000; n. 171, 2018] y Las Puertas del Drama [n. 14, 2003], editadas por las asociaciones de Directores de Escena y de Autores de Teatro, respectivamente, han dedicado números monográficos al teatro para niños. También lo ha hecho la veterana Primer Acto [338 y 339, 2011], y al margen de los monográficos, tanto en las páginas de Primer Acto como en las de ADE Teatro, se han intercalado con frecuencia en los últimos tiempos artículos dedicados a compañías, espacios escénicos y profesionales del teatro para niños que habrá que tener en cuenta en futuras investigaciones. Entre las revistas universitarias, se ha sumado Anagnórisis [n. 5, 2012]. Y en el ámbito de las revistas de literatura infantil, también lo ha hecho Lazarillo, la revista de la Asociación de Amigos del Libro Infantil y Juvenil [n. 24, 2011]. Pero sin duda la revista con más trayectoria en este ámbito es el Boletín Iberoamericano de Teatro para la Infancia y la Juventud, de ASSITEJ-España, que desde 1973 hasta 2011 ha sido la principal publicación en la materia que aquí nos ocupa.

Mucho más reciente que el interés académico hacia el teatro para niños lo es la atención hacia el teatro para adolescentes, y en este sentido contamos con un trabajo importante: el corpus de teatro para jóvenes fue objeto de una Tesis Doctoral leída en 2012, en la que su autora, Isabel Lozano, realizaba un análisis detenido de cada una de las obras, siempre teniendo en cuenta a los alumnos de Secundaria como público, como lectores y como potenciales actores de estas obras [Lozano Palacios 2012]. Además, en el momento de escribir estas páginas acaba de salir de la imprenta un libro monográfico sobre teatro para adolescentes, a cargo de M. Á. Jiménez Aguilar, centrado en el tratamiento de un tema muy concreto como es el acoso escolar [Jiménez Aguilar 2020]. En ambos casos se ofrece un estudio detallado de los textos en cuestión, y ambos resultan imprescindibles para conocer los textos de teatro para jóvenes editados en las colecciones actuales. Al teatro para adolescentes se dedicó igualmente un monográfico en la Revista Digital de la Escena [2011], que editó el Centro de Documentación Teatral ${ }^{5}$.

Como se dijo al principio de este artículo, el Congreso Los márgenes de la periferia [Toledo, 2019] parece marcar un esperanzador cambio de etapa. Los estudios sobre el teatro español no pueden seguir ajenos a todo un conjunto de textos y de espectáculos, de indiscutible calidad e interés en muchos casos, que, a lo largo del siglo XX y de las primeras décadas del XXI, han ido cobrando relevancia en la vida teatral española. Los estudios que hasta ahora se han llevado a cabo, vistos en su conjunto, constituyen un valioso punto de partida para los investigadores del presente y del futuro.

\section{Referencias bibliográficas}

Aguilar Hernández, Cristina (2016): “El Teatro de Arte de los Martínez Sierra encantado por la música y las artes plásticas. Fábulas, cuentos de hadas y, además, teatro para los niños”, en: Ruth Piquer (ed.), Sinergias para la vanguardia española (1898-1936). Granada, Libargo: 221-255.

Aguilera Sastre, Juan e Isabel Lizarraga (eds.) (2018): "Prólogo" a Viajes de una gota de agua, de María Martínez Sierra. Sevilla, Renacimiento.

Ahumada Zuaza, Luis (2011): El teatro infantil y juvenil de Carmen Conde. Tesis Doctoral, Recurso web $<\underline{\text { https://digitum.um.es/ }}$ digitum/handle/10201/29887>, Fecha de consulta: 08-I-20.

- (2012): "Carmen Conde en la historia del teatro infantil español. Semblanza biográfica”, Anagnórisis. Revista de Investigación Teatral, 5: 26-61, Recurso web $<$ http://anagnorisis.es/pdfs/num12.pdf $>$, Fecha de consulta: 06-V-20.

- (2015a): "Teatro infantil y juvenil español: las vanguardias del siglo XX (I)", CLIJ (Cuadernos de Literatura Infantil y Juvenil), 263: 16-29.

En línea: http://teatro.es/contenidos/revistaDigitalDeLaEscena/RDE11 3/aDebate.html, Fecha de consulta: 03.V.2020. 
- (2015b): "Teatro infantil y juvenil español: las vanguardias del siglo XX (y II)", CLIJ (Cuadernos de Literatura Infantil y Juvenil), 264: 6-15.

Anabitarte, Álvaro (2019a): "El teatro infantil en Pamplona: sus inicios", Pregón siglo XXI, 53: 48-51, Recurso web < $<$ http://www. pregonnavarra.com/wp/wp-content/uploads/pdf/d13 ultimo/pregon53/53000-pregon53.pdf $>$, Fecha de consulta: 06-V-20.

— (2019b): "El teatro infantil en la Institución Cunas", Pregón siglo XXI, 54: 80-85.

Aristizabal Llorente, Pilar, et alii. (2013): "Las claves de la comunicación en el teatro para bebés", Aula Abierta, vol. 41, 3: 91100.

Arnaud, Simon (2016): “Censura y teatro para niños en la España franquista (1960-1975): de la censura previa a la 'mediación censora"”, en Pedro César Cerrillo Torremocha y César Sánchez Ortiz (coords.), Prohibido leer: La censura en la literatura infantil y juvenil contemporánea, Cuenca, Universidad de Castilla-La Mancha: 129-138.

- (2018): La transition vers un autre théâtre jeune public: écrire, éditer et mettre en scène en Espagne de 1960 à 1978 . Tesis Doctoral. Université Rennes 2. Recurso web <http://www.theses.fr/2018REN20039>, Fecha de consulta: 08-I-20.

Ayuso, Adolfo (2016): “Otra historia del teatro de títeres en España”, Fantoche. Arte de los Títeres, 10 Extra: 52-73, Recurso web $<$ http://www.unima.es/wp-content/uploads/2017/11/Fantoche-10.pdf $>$, Fecha de consulta: 14-V-20.

Bados Ciria, Concepción (2009): "Intelectuales de la Edad de Plata (14): Concha Méndez y el teatro infantil”, Centro Virtual Cervantes, Recurso web $<$ https://cvc.cervantes.es/el rinconete/anteriores/mayo 09/27052009 02.htm $>$, Fecha de consulta: 08-I-20.

Barrantes, Beatriz (2018): "Literatura infantil femenina en la Generación del 27. Didáctica, modernidad y vanguardia en el teatro para niños de Concha Méndez", Tonos digital: Revista de estudios filológicos, 34, Recurso web < https://digitum.um.es/digitum/ handle/10201/55750>, Fecha de consulta: 08-I-20.

Bernard, Margherita (2006): "Introducción” a: Concha Méndez, El pez engañado. Ha corrido una estrella y Las barandillas del cielo, Madrid, Asociación de Directores de Escena.

Berenguer, Ángel (1988): El teatro en el siglo XX (hasta 1939), Madrid, Taurus.

Borham Puyal, Miriam (2018): "Defensa de la lectura quijotesca en El príncipe que todo lo aprendió en los libros", Ocnos. Revista de Estudios sobre la Lectura, 17, 2: 46-54.

Bravo Villasante, Carmen (1959): Historia de la literatura infantil española, Madrid, Revista de Occidente.

- (1963): Antología de la literatura infantil en lengua española, Madrid, Doncel.

Burguera, María Luisa (1991): "Un ejemplo de análisis de textos teatrales: La cabeza del dragón, de Don Ramón del Valle-Inclán”, Edetania. Estudios y propuestas socio-educativas, 5: 13-28.

Butiñá, Julia (1992): Guía de teatro infantil y juvenil español, Madrid, Asociación Española de Amigos del Libro Infantil y Juvenil.

Butiñá, Julia y Nuria Tubau (1985): "Repertorio bibliográfico. [Obras de teatro infantil y juvenil en lengua castellana, catalana, euskera y gallega]". Boletín Iberoamericano de Teatro para la Infancia y la Juventud, 37 (jul.-sept.): 38-196. Otra ed.: Alicante, Biblioteca Virtual Miguel de Cervantes, 2012, Recurso web $<$ http://www.cervantesvirtual.com/portales/assitej/obra/ boletin-iberoamericano-de-teatro-para-la-infancia-y-la-juventud-38/>, Fecha de consulta: 08-I-20.

Butiñá, Julia, Ana Llorente y Berta Muñoz (2002): Guía de teatro infantil y juvenil, Madrid, Asociación Española de Amigos del Libro Infantil y Juvenil, ASSITEJ-España, Universidad Nacional de Educación a Distancia. Otra edición: Alicante, Biblioteca

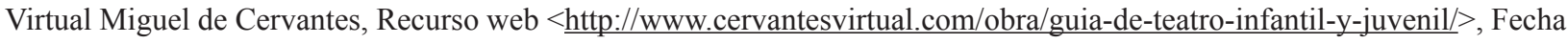
de consulta: 08-I-20.

Centro de Documentación de las Artes Escénicas y de la Música (antes Centro de Documentación Teatral) (1985-2020): Estrenos Teatrales (1939-2020), Madrid, Ministerio de Cultura y Deporte, Recurso web $<$ http://teatro.es/estrenos-teatro $>$, Fecha de consulta: $15-\mathrm{V}-20$.

Centro de Documentación de las Artes Escénicas y de la Música (2011-2019): Documentos para la Historia del Teatro Español (1939-1948), Madrid, Ministerio de Cultura y Deporte, Recurso web $<\underline{\text { http://teatro.es/contenidos/documentosParaLaHistoria/ }}$ Docs1948/index.html?3>, Fecha de consulta: 08-I-20.

Cerrillo Torremocha, Pedro y Maria Teresa Miaja (2013): La literatura infantil y juvenil española en el exilio mexicano, Cuenca, Universidad de Castilla-La Mancha.

Cervera, Juan (1982): Historia crítica del teatro infantil español, Madrid, Editora Nacional.

Etxaniz Erle, Xabier (2007): "Panorama histórico do teatro infantil en vasco (Euskal haur antzerkigintzaren panorama historikoa”, en Blanca Ana Roig Rechou, Pedro Lucas Domínguez, Isabel Soto López, Isabel (coords.), Teatro Infantil. Do texto á representación, Vigo, Xerais: 87-98. Otra ed.: Alicante, Biblioteca Virtual Miguel de Cervantes. Recurso web $<$ http://www. cervantesvirtual.com/descargaPdf/teatro-infantil-do-texto-a-representacion/>, Fecha de consulta: 08-I-20.

Fernández Cambria, Elisa (1987): Teatro español de siglo XX para la infancia y la juventud. (Desde Benavente hasta Alonso Santos), Madrid, Escuela Española.

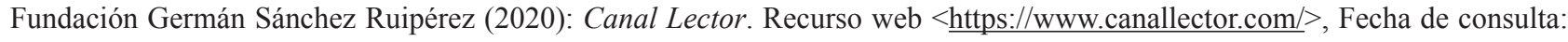
06-V-20.

García Padrino, Jaime (1992): Libros y literatura para niños en la España contemporánea, Madrid, Fundación Germán Sánchez Ruipérez / Pirámide.

- (2018): Historia crítica de la literatura infantil y juvenil en la España actual, Madrid, Marcial Pons. 
García de Rivera Hurtado, Mª Antonia (2010): El teatro escolar en la época contemporánea (1870-1970). Catalogación de 1.001 textos dramáticos escolares. Tesis Doctoral. Universidad Nacional de Educación a Distancia, Recurso web $<\underline{\text { http://e-spacio. }}$ uned.es/fez/eserv/tesisuned:Educacion-Magarcia/Documento.pdf>, Fecha de consulta: 04-V-20.

García Ruiz, Víctor y Gregorio Torres Nebrera (dirs.) (2002-2006): Historia y antología del teatro español de posguerra, Madrid, Fundamentos (7 vols.).

Gisbert i Muñoz, Francesc (2015): Autors i tendències de la literatura infantil i juvenil valenciana (1975-2014). Tesis Doctoral. Universidad de Alicante. Recurso web $<$ https://rua.ua.es/dspace/bitstream/10045/51857/1/tesis_gisbert_munoz.pdf $>$, Fecha de consulta: $15-\mathrm{V}-20$.

Gobbé-Mévellec, Euriell (2012): “Luis Matilla et le «teatro de animación»: une alternative à l'image hypermedia depuis la scène?", Anagnórisis. (Revista de Investigación Teatral), 5: 62-84, Recurso web <http://www.anagnorisis.es/pdfs/n5/gobbemevellec(62-84) n5.pdf >, Fecha de consulta: 05-V-20.

Hernández Sánchez, Mario (1992): "Falla, García Lorca y Lanz en una sesión granadina de títeres (1923)”, en Dru Dougherty y María Francisca Vilches de Frutos (coords.), El teatro en España: entre la tradición y la vanguardia (1918-1939), Madrid, Consejo Superior de Investigaciones Científicas y Fundación García Lorca: 227-240.

Hormigón, Juan Antonio (dir.) (1996): Autoras en la historia del teatro español (1500-1994), Madrid, Asociación de Directores de Escena (2 vols.).

Huerta Calvo, Javier (dir.) (2003): Historia del teatro español, Madrid, Gredos (2 vols.).

— (2012): "El Teatro de los Niños de Jacinto Benavente", Don Galán. (Revista de Investigación Teatral), 2, Recurso web < teatro.es/contenidos/donGalan/donGalanNum2/pagina.php?vol=2\&doc=2_1>, Fecha de consulta: 01-I-20.

González Subías, José Luis (2019): Literatura y Escena. Una historia del teatro español, Madrid, Punto de Vista Editores.

Lara Alberola, Eva (2010): "El Entremés nuevo intitulado el incrédulo de bruxas y malcreiente de duendes del Padre Villarroya. La bruja como máscara en el drama escolar del siglo XVIII: un puente hacia el teatro infantil". TeatrEsco, 4: 1-27, Recurso

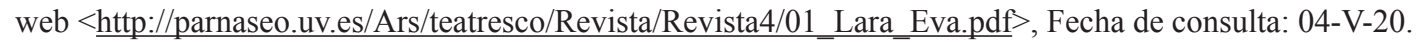

López Askasibar, Xavier (2011): Tocar el teatro con las manos o El teatro para niños de Luis Matilla, Madrid, ASSITEJ-España, Recurso web $<$ http://www.cervantesvirtual.com/obra/tocar-el-teatro-con-las-manos-o-el-teatro-para-ninos-de-luis-matilla/ $>$, Fecha de consulta: 04-V-20.

- (2018): "Teatro para público infantil de Luis Matilla durante la Transición Española", Las Puertas Del Drama. (Revista de la Asociación de Autores de Teatro), 51, Recurso web < http://www.aat.es/elkioscoteatral/las-puertas-del-drama/drama-51/ teatro-para-publico-infantil-de-luis-matilla-durante-la-transicion-espanola/>, Fecha de consulta: 04-V-20.

López Tamés, Ramón (1990): Introducción a la Literatura Infantil, Murcia, Universidad de Murcia. Otra edición: Alicante, Biblioteca Virtual Miguel de Cervantes, 2010. Recurso web $<$ http://www.cervantesvirtual.com/obra/introduccion-a-laliteratura-infantil/>, Fecha de consulta: 04-V-20.

Lozano Palacios, Isabel (2012): Aproximación a la literatura dramática juvenil actual: Definición, determinación del corpus $y$ análisis. Universidad de Alcalá de Henares, Recurso web $<$ https://ebuah.uah.es/dspace/bitstream/handle/10017/14003/ M\%C2\%AA\%20Isabel\%20Lozano\%20-\%20Tesis\%20doctoral.pdf?sequence=1\&isAllowed=y $>$, Fecha de consulta: 09-V20.

Luna, Marta (2007): "Panorama historie del teatre infantil en catalá”, en Blanca Ana Roig Rechou, Pedro Lucas Domínguez, Isa-

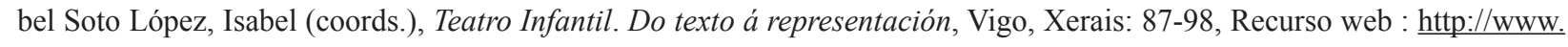
cervantesvirtual.com/descargaPdf/teatro-infantil-do-texto-a-representacion/>, Fecha de consulta: 09-V-20.

Mascarell, Purificación (2018): "El teatro infantil de Elena Fortún y la canción de raigambre popular", Anagnórisis. Revista de Investigación Teatral, 18, 59-77, Recurso web <http://anagnorisis.es/pdfs/num18.pdf $>$, Fecha de consulta: 06-V-20.

Mendoza Fillola, Antonio (1980): El Teatro Infantil Español. Aspectos sociales (1875-1950). Tesina de Licenciatura inédita. Ejemplar microfilmado conservado en la Biblioteca Nacional, signatura: DGMICRO/21833.

- (1998): "El Teatro Infantil Español. Aspectos sociales”, en María Rosa Cabo Martínez (coord.), La literatura infantil y juvenil, su proyección en el aula: V Simposio Internacional de la Sociedad Española de Didáctica de la Lengua y la Literatura, Oviedo, Universidad de Oviedo: 21-49.

Molina Angulo, Raquel (2018-2019): "La comicidad en el teatro infantil de Concha Méndez", Scriptura (Ejemplar dedicado a: Estudios sobre teatro hispánico en homenaje a Josep M. Sala Valldaura), 26: 109-118.

- (2019): El teatro infantil en la primera mitad del siglo XX: Implicaciones pedagógicas en la obra de Elena Fortún, Magda Donato y Concha Méndez. Tesis Doctoral (inédita). Universitat de Lleida.

Molina Angulo, Raquel y Moisés Selfa Sastre (2019): "El teatro femenino de preguerra en España: Elena Fortún y su Teatro para niños (1936)", Revista de Literatura, vol. 81, 161: 153-175.

Mora Álvarez, Ma Teresa (2015): "El teatro escolar de Alfonso Jiménez Romero”, Don Galán. (Revista de Investigación Teatral), 5, Recurso web $<$ http://teatro.es/contenidos/donGalan/donGalanNum5/pagina.php?vol=5\&doc=2_3\&el-teatro-escolar-dealfonso-jimenez-Romero\&maria-teresa-mora-alvarez $>$, Fecha de consulta: 06-V-20.

Muñoz, Juan y Elena Muñoz (2017): Construyendo La Tartana Teatro, Madrid, La Tartana.

Muñoz Cáliz, Berta (2001): "Teatro infantil. Un año de sequía editorial, con algunas excepciones", Lazarillo. (Revista de la Asociación de Amigos del Libro Infantil y Juvenil), 6: 80-84.

- (2003): “Teatro infantil y juvenil. Un género por descubrir”, Lazarillo. (Revista de la Asociación de Amigos del Libro Infantil y Juvenil), 9: 47-52. 
— (2004): "Teatro infantil y juvenil: textos para la lectura y para la representación”, Lazarillo. (Revista de la Asociación de Amigos del Libro Infantil y Juvenil), 11: 51-57.

- (2005): "Libros de teatro para niños y jóvenes: espejo en el que divertirse y en el que encontrarse", Lazarillo. (Revista de la Asociación de Amigos del Libro Infantil y Juvenil), 13: 58-62.

- (2006): Panorama de los textos teatrales para niños y jóvenes, Madrid, ASSITEJ-España. (Premio Juan Cervera de Investigación sobre Teatro para la Infancia y la Juventud).

- (2006b): "Los textos teatrales: una lectura atractiva y necesaria”, Lazarillo. (Revista de la Asociación de Amigos del Libro Infantil y Juvenil), 15: 57-63.

- (2007): "Teatro: el juego de escuchar al contrario", Lazarillo. (Revista de la Asociación de Amigos del Libro Infantil y Juvenil), 17: $67-72$.

- (2008): "El teatro: entre la tradición y la renovación", Lazarillo. (Revista de la Asociación de Amigos del Libro Infantil y Juvenil), 19: 67-73.

- (2009): “2008: La crisis también alcanzó al teatro para niños”, Lazarillo. (Revista de la Asociación de Amigos del Libro Infantil y Juvenil), 21: 62-68.

- (2010): "Un buen año de teatro para adolescentes", Lazarillo. (Revista de la Asociación de Amigos del Libro Infantil y Juvenil), 23: 61-68.

— (2011): "El teatro [infantil] durante la dictadura franquista y la Transición política", Primer Acto. (Cuadernos de Investigación Teatral), 338: 9-21.

- (2012): "El teatro para niños y jóvenes de Jesús Campos”, Anagnórisis. (Revista de Investigación Teatral), 5: 85-113. Recurso web $<$ http://www.anagnorisis.es/pdfs/n5/munoz_caliz(85-113)_n5.pdf $>$, Fecha de consulta: 05-V-20.

- (2016): "Falangismo y teatro infantil: el teatro para niños en la inmediata posguerra a través de la prensa del período (19391942)", en M. Franco y B. Riesgo, La infancia y sus metamorfosis. (España 1920-1975), Centre de Recherche sur l'Espagne Contemporaine, Université de la Sorbonne Nouvelle - Paris 3: 177-199.

Muñoz Cáliz, Berta y María Victoria Sotomayor Sáez (2016): “Censura y teatro infantil”, en Pedro César Cerrillo Torremocha (ed. lit.) y María Victoria Sotomayor Sáez (ed. lit.), Censuras y literatura infantil y juvenil en el siglo XX: (en España y 7 países latinoamericanos), Cuenca, Universidad de Castilla-La Mancha: 183-216.

Nieva de la Paz, Pilar (1993a): Autoras dramáticas españolas entre 1918 y 1936. Madrid, Consejo Superior de Investigaciones Científicas.

— (1993b): "Las escritoras españolas y el teatro infantil de preguerra: Magda Donato, Elena Fortún y Concha Méndez”, Revista de Literatura, Tomo LV, 109: 113-128.

- (2001): "El teatro infantil de Concha Méndez”, en James Valender (ed.), Una mujer moderna. Concha Méndez en su mundo, Madrid, Residencia de Estudiantes: 165-176.

Oliva, César (1989): El teatro desde 1936, Madrid, Alhambra.

Pascual, Itziar (ed.) (2008): Teatro español para la infancia y la juventud (1800-1936), Madrid, Fundamentos. (Con textos de Francisco Pi y Arsuaga, Sinesio Delgado y Manuel Linares Rivas).

Rodríguez, Javo (2003): "Libro recomendado: Historia crítica del teatro infantil español, de Juan Cervera", Las Puertas del Drama. (Revista de la Asociación de Autores de Teatro), 14: 40-41.

Rodríguez González, M. ${ }^{a}$ Remedios (2017): El teatro infantil en la producción dramática de José Luis Alonso de Santos, Tesis Doctoral. Universidad de Alcalá, Recurso web $<$ https://ebuah.uah.es/dspace/handle/10017/38242>, Fecha de consulta: 05-V-20.

Rodríguez Lorenzo, Gloria Araceli (2018): "Los nietos del Capitán Grant: Teatro y música en las compañías infantiles de Luis Blanc y Juan Bosch (1877-1897)”, en José Ignacio Suárez García (ed. lit.), Ramón Sobrino Sánchez (ed. lit.) y María Encina Cortizo Rodríguez (ed. lit.), Música lírica y prensa en España (1868-1936): ópera, drama lírico y zarzuela, Oviedo, Universidad de Oviedo: 283-300.

Roig Rechou, Ana y María López Suárez (2007): "Panorama histórico do teatro infantil en galego”, en Blanca Ana Roig Rechou, Pedro Lucas Domínguez, Isabel Soto López, Isabel (coords.), Teatro Infantil. Do texto á representación, Vigo, Xerais: 99122, Recurso web $<$ http://www.cervantesvirtual.com/descargaPdf/teatro-infantil-do-texto-a-representacion/, Fecha de consulta: $05-\mathrm{V}-20$.

Rubio Jiménez, Jesús (1987): “La cabeza del dragón. El final del ensueño modernista”, Hispanística, XX, 5: 37-51.

Ruiz, María Jesús (2008a): "De Sanabria a Buenos Aires. El destierro escénico de Alejandro Casona”, en Ana Pelegrín, M. ${ }^{a}$ Victoria Sotomayor y Alberto Urdiales (eds.), Pequeña memoria recobrada. Libros infantiles del exilio del 39, Madrid, Ministerio de Educación.

- (2008b): "Vieja tradición oral y nueva pedagogía. El teatro infantil de Alejandro Casona", en Pedro C. Cerrillo Torremocha y César Sánchez Ortiz (coords.), La palabra y la memoria. (Estudios sobre literatura popular infantil), Cuenca, Ediciones de la Universidad de Castilla-La Mancha: 363-390.

- (2016), “Un siglo de teatro de títeres en España: entre el arte y la pedagogía. Una aproximación”, en M. Franco y B. Riesgo, La infancia y sus metamorfosis. (España 1920-1975), Centre de Recherche sur l'Espagne Contemporaine, Université de la Sorbonne Nouvelle - Paris 3: 155-176.

Ruiz Ramón, Francisco (1967): Historia del Teatro Español (I y II), Madrid, Cátedra. Ed. ampliadas: 1975 y ss.

Sánchez Laílla, Luis (2004): “La cabeza del dragón, farsa infantil de Valle-Inclán”, Revista de humanidades: Tecnológico de Monterrey, 16: 119-148. 
Santolaria, Cristina (2001): "Dramaturgos consagrados se acercan al teatro para la infancia y la juventud", Teatro. (Revista de Estudios Teatrales), 13-14: 459-487

Sotomayor Sáez, María Victoria (2007): “Literatura dramática infantil: texto y representación”, en Blanca Ana Roig Rechou, Pedro Lucas Domínguez, Isabel Soto López, Isabel (coords.), Teatro Infantil. Do texto á representación, Vigo, Xerais: 11-36, Recurso web $<$ http://www.cervantesvirtual.com/descargaPdf/teatro-infantil-do-texto-a-representacion/ $>$, Fecha de consulta: $5-\mathrm{V}-20$.

— (2008): "Memoria de la escena: el teatro infantil de los exiliados", en Ana Pelegrín, M. a Victoria Sotomayor y Alberto Urdiales, Pequeña memoria recobrada. Libros infantiles del exilio del 39, Madrid, Ministerio de Educación, Cultura y Deporte: 93-118.

Tejerina Lobo, Isabel (1993): Estudio de los textos teatrales para niños, Santander, Universidad de Cantabria.

- (1994a): Dramatización y teatro infantil: dimensiones psicopedagógicas y expresivas, Madrid, Siglo XXI de España.

- (1994b): "Análisis funcional y sintaxis y semántica de personajes en Pinocho y Blancaflor de Alejandro Casona”, Letras de Deusto, vol. 24, 62: 133-157. Otra ed.: Alicante, Biblioteca Virtual Miguel de Cervantes, 2005, Recurso web <http://www. cervantesvirtual.com/obra/anlisis-funcional-y-sintaxis-y-semntica-de-personajes-en-pinocho-y-blancaflor-de-alejandrocasona-0/>, Fecha de consulta: 07-V-20.

- (1998): "Claves estructurales y estilísticas del teatro para niños: las farsas de Alejandro Casona”, en M. Rosa Cabo Martínez (coord.), La literatura infantil y juvenil. Su proyección en el aula. (V Simposio Internacional de la Sociedad Española de Didáctica de la Lengua y la Literatura), Oviedo, Servicio de Publicaciones de la Universidad de Oviedo: 79-89.

- (2000): "La literatura infantil y el teatro de títeres: de García Lorca hasta la actualidad", en Ramón F. Llorens García (coord.), La literatura infantil en la escuela, Alicante, Universidad de Alicante: 55-67, Recurso web $<\underline{\text { http://www.cervantesvirtual. }}$ com/obra-visor/literatura-infantil-en-la-escuela--0/html/ff2f6bf0-82b1-11df-acc7-002185ce6064_10.html\#I_24_>, Fecha de consulta: 07-V-20.

- (2001): “Didáctica del texto dramático y La cabeza del dragón, de Valle-Inclán”, en E. Menéndez y A. Delgado (eds.), Lengua y Cultura. Enfoques didácticos, Las Palmas de Gran Canaria, Universidad, 703-715. Otra ed.: Alicante, Biblioteca Virtual Miguel de Cervantes, 2005, Recurso web $<$ http://www.cervantesvirtual.com/obra/didctica-del-texto-dramtico-y-la-cabezadel-dragn-de-valle-incln-0/>, Fecha de consulta: 05-V-20.

- (2007): "Panorama histórico del teatro infantil en castellano", en Blanca Ana Roig Rechou, Pedro Lucas Domínguez, Isabel Soto López, Isabel (coords.), Teatro Infantil. Do texto á representación, Vigo, Xerais: 57-84. Otra ed.: Alicante, Biblioteca Virtual Miguel de Cervantes, Recurso web $<$ http://www.cervantesvirtual.com/obra/panorama-historico-del-teatroinfantil-en-castellano/>, Fecha de consulta: 05-V-20.

Toral, Carolina (1957): Literatura infantil española, Madrid, Coculsa (2 vols.).

Vela Cervera, David (2004): Salvador Bartolozzi (1881-1950): Ilustración gráfica. Escenografia. Narrativa y teatro para niños, Alicante, Biblioteca Virtual Miguel de Cervantes (Edición digital a partir del texto original de la Tesis Doctoral), Recurso web <http://www.cervantesvirtual.com/obra/salvador-bartolozzi-18811950-ilustracion-grafica-escenografia-narrativa-yteatro-para-ninos--0/>, Fecha de consulta: 05-V-20.

Vicente Hernando, César de (2000): “Introducción” a: Magda Donato, Pipo, Pipa y el lobo Tragalotodo. Pinocho en el País de los Cuentos. Madrid, Asociación de Directores de Escena.

Yousfi López, Yasmina (2019): La labor teatral de Josefina Plá. Una escritora en la frontera. (Tesis Doctoral). Universidad

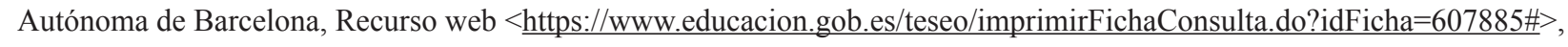
Fecha de consulta: 14-V-20. 